\title{
Spectacle Independence and Quality of Vision After Bilateral Implantation of a Trifocal Intraocular Lens
}

\author{
Andrew C Shatz' \\ Richard Potvin $\mathbb{D}^{2}$ \\ 'SightTrust Eye Institute, Sunrise, FL, \\ USA; ${ }^{2}$ Science in Vision, Bend, OR, USA
}

Correspondence: Andrew C Shatz SightTrust Eye Institute, 160I Sawgrass Corporate Pkwy, Suite 430, Sunrise, FL, 33323, USA

Email ashatz@sighttrust.com
Purpose: To evaluate the patient-reported spectacle independence and quality of vision for patients who were bilaterally implanted with a trifocal intraocular lens (IOL).

Design: Single site, prospective, single-arm study.

Methods: Subjects presenting for cataract surgery who had an interest in reducing their dependence on glasses at multiple distances were enrolled. Subjects were bilaterally implanted with a trifocal IOL and followed for 3 months post-surgery. A spectacle independence questionnaire and a quality of vision questionnaire were administered at the 3-month visit. The binocular visual acuity at distance $(4 \mathrm{~m})$, intermediate $(60 \mathrm{~cm})$ and near $(40 \mathrm{~cm})$ was also measured in the uncorrected and distance-corrected state.

Results: All but one subject reported no need for glasses for distance and intermediate work, and most (25/29) reported no need for glasses for near work. Almost all subjects reported never wearing glasses or wearing them only a little, and being able to function without glasses at any distance all or most of the time. Ninety percent of subjects (26/29) reported being completely or mostly satisfied with their vision overall, without the use of glasses or contact lenses. The mean binocular visual acuity 1 and 3 months after surgery was better than $0.1 \operatorname{logMAR}(20 / 25)$ at all test distances in both the uncorrected and distance-corrected states. The reported quality of vision appeared similar to previously reported data for the same IOL.

Conclusion: The trifocal IOL provided nearly all subjects with functional vision and spectacle independence for distance, intermediate and near work. It is a viable alternative for patients looking to reduce their overall dependence on spectacles after cataract surgery. Keywords: panoptix, trifocal IOL, presbyopia correction, cataract surgery, spectacle independence

\section{Plain Language Summary}

Patients having cataract surgery are often offered alternative lenses that are intended to reduce their need for glasses to function at various distances, from driving to reading. The lenses that are believed to best improve vision at distance, intermediate (computer distance) and near (reading) are called trifocal intraocular lenses (IOLs). These lenses can focus light at all three of the distances described above.

Our study was designed to determine whether patients implanted with trifocal lenses achieved a high level of spectacle independence at a variety of working distances, from far to near. We were also interested in learning whether they were satisfied with their vision, and whether they experienced any visual disturbances such as glare or halos.

The clarity of vision achieved at the tested distances was very good. Nearly all subjects reported being able to function without glasses or contact lenses most or all of the time at all 
working distances. Nine of ten subjects were completely or mostly satisfied with overall vision after surgery. Trifocal IOLs appear to be a good vision correction option for patients. Patients should be aware that dry eye can affect results, and should expect that halos may be experienced.

\section{Introduction}

Patients presenting for cataract surgery are often interested in options to reduce their dependence on spectacles for a variety of tasks, from distance vision to computer work (intermediate vision) and/or reading (near vision). Intraocular lens (IOL) options are available for a variety of patient needs. The major considerations for the patient are usually the distances at which they desire spectacle independence and whether the slightly increased potential for visual disturbances is likely to be a bother to them. Currently, the best option for those who desire good vision at distance, intermediate and near is likely to be a trifocal IOL, which provides 3 distinct foci at those distances. Trifocal IOLs have been shown to provide better intermediate vision than is obtained with a bifocal IOL $\operatorname{design}^{1,2}$ and to provide better near vision than can be obtained with an extended depth of focus IOL., 3

Early trifocal IOL designs were constrained by their optics to provide an intermediate focus that was half the dioptric distance of the near focus. For instance, the FineVision trifocal (PhysIOL, Liège, Belgium) design included a $1.75 \mathrm{D}$ and $3.50 \mathrm{D}$ intermediate and near focus respectively, corresponding to roughly $80 \mathrm{~cm}$ for intermediate viewing and $40 \mathrm{~cm}$ for near viewing. ${ }^{5}$ These values are similar to those reported for the AT Lisa tri IOL (Carl Zeiss Meditec, Jena, Germany), with a 1.66 D intermediate add and a 3.33 D near add. ${ }^{6}$ The best intermediate focus for both of these trifocals is thus located further than where most patients place a computer or hold a cellphone or tablet; in the latter two cases "arm's length" is often a limiting factor. ${ }^{7}$ With traditional trifocal designs, the only way the intermediate add could be increased was if there was a corresponding increase in the near add - an undesirable side effect as the optimal reading distance would be moved closer than $40 \mathrm{~cm}$.

The PanOptix ${ }^{\circledR}$ Trifocal IOL (Alcon, Fort Worth, USA) is currently the only trifocal IOL approved by the FDA for use in the USA. It is fundamentally based on an aspheric diffractive quadrifocal IOL design, but the light at the first focal point is redirected to improve distance vision, making it a trifocal IOL in function. The benefit of this design is that it redistributes light energy in a unique manner to provide focal points at distance, intermediate $(60 \mathrm{~cm})$ and near $(40 \mathrm{~cm}) .{ }^{8}$ Studies of the PanOptix IOL have shown improved intermediate vision at $60 \mathrm{~cm}$ relative to the traditional trifocal IOLs described above. ${ }^{9-11}$ Prior reported clinical results indicate that the lens provides a good range of vision $(\sim 3 \mathrm{D})$ with contrast sensitivity values in the normal range. ${ }^{12-14}$

The purpose of the current study was to provide normative spectacle independence, quality of vision and visual acuity data related to bilateral implantation of the PanOptix trifocal IOL.

\section{Methods}

This study was a single-site prospective single-arm study of clinical and subjective visual outcomes after bilateral implantation of a trifocal IOL. The study was approved by an institutional review board (Salus IRB, Austin, TX, USA). All subjects signed an appropriate informed consent document. The study was conducted in compliance with Good Clinical Practice (GCP), the tenets of the Declaration of Helsinki and International Harmonization (ICH) guidelines. The study was registered with clinicaltrials.gov (NCT04124952). Data are not available for sharing.

Subjects over 40 years of age who were eligible for cataract surgery and interested in a reduced dependence on spectacles for near, intermediate and distance vision were considered for enrollment. They had to be considered appropriate candidates for trifocal IOL implantation (toric or non-toric) with no preoperative ocular pathology (eg corneal dystrophy, diabetic retinopathy), prior corneal or intraocular surgery, or any other pre-existing condition likely to confound the results of the study. All potential multifocal patients in the practice complete a lifestyle questionnaire and are individually counseled by the surgeon regarding the need for good lighting when reading, the need to manage dry eye and the potential to see halos around lights when driving at night for at least several months post-operatively. Candidates for any multifocal IOL must have $20 / 30$ or better potential acuity in both eyes.

Subjects were bilaterally implanted with the trifocal IOL on the same day and followed for 3 months after surgery, with refractive and VA data collected at both 1 and 3 months postoperative. Quality of vision and spectacle independence questionnaires were completed at the 3-month visit. All subjects were monitored for adverse 
events over the course of the study. The primary measure of interest was the reported level of spectacle wear for distance, intermediate and near vision, and overall, 3 months postoperative; this was based on responses to the Patient Reported Spectacle Independence Questionnaire, or PRSIQ. ${ }^{15}$ Secondary measures included binocular visual acuities (uncorrected and best distance-corrected) at distance $(4 \mathrm{~m})$, intermediate $(60 \mathrm{~cm})$ and near $(40 \mathrm{~cm})$ at the 1-month and 3-month postoperative visits. The Quality of Vision questionnaire, a Rasch-scored questionnaire related to the frequency, severity, and degree of bother of various potential visual disturbances, was used to evaluate subjectively reported quality of vision. ${ }^{16}$

All clinical data and questionnaire responses were tabulated in Microsoft Access (Microsoft, Redmond, WA, USA). Statistical analyses were performed using Statistica 12 (TIBCO Software Inc., Palo Alto, CA, USA). As a single-arm study, results were generally limited to descriptive statistics. Where appropriate, statistical testing of parametric variables was based on an analysis of variance (ANOVA), with a level of statistical significance of $\mathrm{p} \leq 0.05$. While a specific sample size for a single-arm study could not be calculated, a sample of 30 subjects $(60$ eyes) was considered reasonable to characterize the performance of this trifocal IOL.

\section{Results}

A total of 30 subjects were enrolled in the study, with all subjects bilaterally implanted with a non-toric or toric trifocal IOL between 10/2019 and 10/2020. One subject was lost to follow-up after successful bilateral IOL implantation (no 1-month or 3-month data available), leaving 29 subjects completing the study. One subject missed their 1 month visit due to a COVID-19 closure. Table 1 summarizes the demographic, preoperative and operative characteristics of the group. While not shown, mean IOL power was not statistically significantly different between the toric and non-toric eyes $(p=0.20)$.

Table I Demographic, Preoperative and Operative Summary

\begin{tabular}{|l|c|}
\hline \multicolumn{2}{|c|}{29 Subjects, 58 Eyes } \\
\hline Age (years) & $58 \pm 7(45 \text { to } 70)^{*}$ \\
Female/Male & $17 / 12$ \\
Non-toric/Toric & $42 / 16$ \\
IOL power (D) & $19.0 \pm 4.1$ (II.0 to 27.0$)^{*}$ \\
\hline
\end{tabular}

Note: *Mean \pm standard deviation (range)

Abbreviation: D, diopter.
The PRSIQ results are summarized in Table 2. As can be seen, only one subject reported needing glasses for distance work and one needed glasses for intermediate work. A significant majority $(25 / 29,86 \%)$ reported no need for glasses for near work. Almost all subjects reported never wearing glasses or wearing them only a little, and being able to function without glasses at any distance all or most of the time. Ninety percent of subjects (26/29) reported being completely satisfied or mostly satisfied with their vision without glasses or contact lenses overall. The two least-satisfied subjects were both observed to have dry eye postoperatively, with variable visual acuity and refractive results.

The Quality of Vision questionnaire measures the reported frequency, severity and degree of bother associated with 10 different potential visual disturbances, then provides an aggregate Rasch-scored (1-100 scale) result for each. Figure 1 shows the distribution of aggregate results for these three patient-reported characteristics. Table 3 summarizes the reported frequency, severity, and degree of bother for haloes, glare, and starbursts. Haloes were the most frequently reported visual disturbance, with $41 \%$ of subjects (12/29) rating them as "moderate" or "severe". Haloes were also rated as the most bothersome; $20 \%(6 / 29)$ of subjects reported halos as "quite" or "very" bothersome. Glare and starbursts were the next most frequent disturbances noted but were reported less frequently and as less bothersome than haloes. The higher outliers were associated with the two subjects with dry eye, identified above.

The mean monocular spherical equivalent refraction at 3 months was $0.06 \pm 0.53 \mathrm{D}$, while the mean residual refractive cylinder was $0.49 \pm 0.36 \mathrm{D}$. Mean binocular visual acuity results at 1 month and 3 months are shown in Figure 2 (uncorrected) and Figure 3 (distance-corrected) . The mean visual acuity was better than $0.1 \log$ MAR (20/ 25) at all distances in both the uncorrected and distancecorrected states at both time points. There was no statistically significant difference in any VA measure between 1 and 3 months postoperative. At the 3-month visit, binocular distance-corrected acuity was slightly better (less than half a line) than uncorrected acuity at $4 \mathrm{~m}(\mathrm{p}<0.01)$ but not statistically significantly different at $60 \mathrm{~cm}(\mathrm{p}=0.16)$ or $40 \mathrm{~cm}(\mathrm{p}=0.33)$.

There was one unrelated non-serious adverse event reported for one subject during the study. They had a bicycle accident with minor injuries, none of which involved the eye. There was no apparent effect on their 
Table 2 PRSIQ Summary Data $(\mathrm{n}=29)$

\begin{tabular}{|c|c|c|c|c|c|c|}
\hline Need Glasses for & Yes & No & $\%$ No & & & \\
\hline Distance & I & 28 & $97 \%$ & & & \\
\hline Intermediate & I & 28 & $97 \%$ & & & \\
\hline Near & 4 & 25 & $86 \%$ & & & \\
\hline Wear glasses or contacts for & All the time & $\begin{array}{l}\text { Most of } \\
\text { the time }\end{array}$ & $\begin{array}{l}\text { Some of the } \\
\text { time }\end{array}$ & $\begin{array}{l}\text { A little of } \\
\text { the time }\end{array}$ & $\begin{array}{l}\text { None of } \\
\text { the time }\end{array}$ & $\begin{array}{c}\% \text { None or a little of } \\
\text { the time }\end{array}$ \\
\hline Distance & & & I & & 28 & $97 \%$ \\
\hline Intermediate & 1 & & & & 28 & $97 \%$ \\
\hline Near & & I & & 4 & 24 & $97 \%$ \\
\hline Overall & & & & 2 & 27 & $100 \%$ \\
\hline $\begin{array}{l}\text { Function comfortably without } \\
\text { glasses or contacts }\end{array}$ & All the time & $\begin{array}{l}\text { Most of } \\
\text { the time }\end{array}$ & $\begin{array}{l}\text { Some of the } \\
\text { time }\end{array}$ & $\begin{array}{l}\text { A little of } \\
\text { the time }\end{array}$ & $\begin{array}{l}\text { None of } \\
\text { the time }\end{array}$ & $\begin{array}{c}\% \text { All or Most of the } \\
\text { time }\end{array}$ \\
\hline Distance & 28 & & & I & & $97 \%$ \\
\hline Intermediate & 26 & 2 & & & $\mathrm{I}$ & $97 \%$ \\
\hline Near & 24 & 2 & & 2 & $\mathrm{I}$ & $90 \%$ \\
\hline Overall & 25 & 3 & I & & & $97 \%$ \\
\hline $\begin{array}{l}\text { Satisfaction with vision without } \\
\text { glasses or contacts }\end{array}$ & $\begin{array}{l}\text { Completely } \\
\text { satisfied }\end{array}$ & $\begin{array}{l}\text { Mostly } \\
\text { satisfied }\end{array}$ & $\begin{array}{l}\text { Moderately } \\
\text { satisfied }\end{array}$ & $\begin{array}{l}\text { A little } \\
\text { satisfied }\end{array}$ & $\begin{array}{l}\text { Not at all } \\
\text { satisfied }\end{array}$ & $\begin{array}{l}\% \text { Completely or } \\
\text { Mostly Satisfied }\end{array}$ \\
\hline Distance & 19 & 6 & 3 & & $\mathrm{I}$ & $86 \%$ \\
\hline Intermediate & 19 & 6 & 3 & I & & $86 \%$ \\
\hline Near & 18 & 6 & 2 & 2 & I & $83 \%$ \\
\hline Overall & 19 & 7 & 3 & & & $90 \%$ \\
\hline
\end{tabular}

Abbreviation: PRSIQ, patient reported spectacle independence questionnaire.

study results. The accident was unrelated to the cataract surgery.

\section{Discussion}

The current study was designed to collect spectacle independence, subjective quality of vision and visual acuity

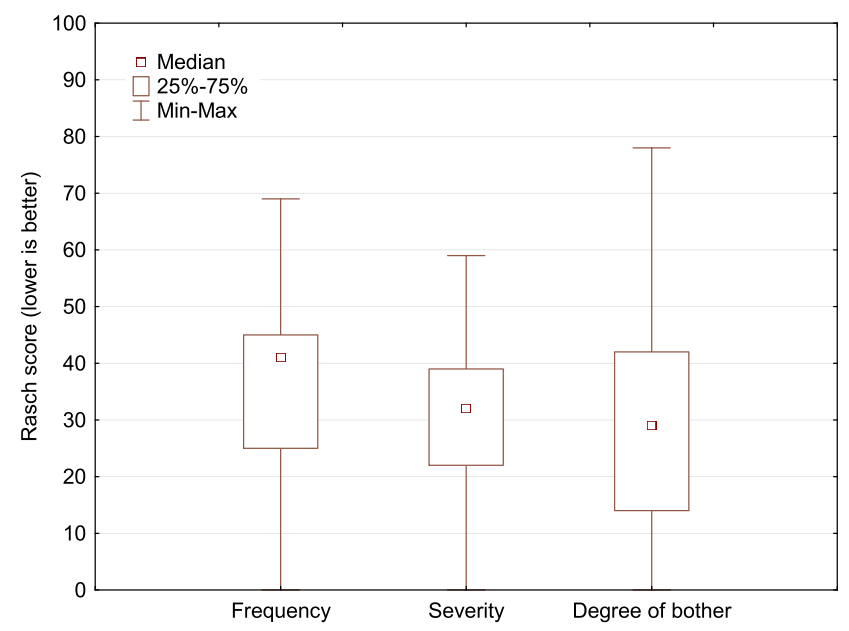

Figure I Box whisker plot showing the distribution of the Quality of Vision aggregate scores (lower is better). data for the only trifocal IOL currently approved for use in the USA, with an emphasis on the degree of spectacle independence achieved.

Previous studies have used different tests of patient functional vision and spectacle independence, or different scoring, so it is difficult to directly compare results. However, overall spectacle independence reported by Donmez et al for the same trifocal IOL was $94 \%$, ${ }^{17}$ while Cochener reported $90 \%{ }^{3}$ both results appear consistent with findings in the current study. The highest reported need for spectacles at any distance in the current study (14\%) was slightly lower than reported in the study performed to obtain FDA approval for the lens $(19.5 \%)$, ${ }^{18}$ indicating somewhat better results in the current study. The distance at which spectacles were needed most often was $40 \mathrm{~cm}$ (near vision) in both studies.

In the current study, $90 \%$ of subjects reported that they were completely or mostly satisfied with their vision overall, which appears consistent with the findings of Garcia-Perez et $\mathrm{al}^{19}$ and Rementeira-Capelo et $\mathrm{al}^{4}$, though the questionnaires used in all 3 studies were different. At present, there is no standardized questionnaire related to spectacle 
Table 3 Frequency, Severity and Degree of Bother for Select Visual Disturbances $(n=29)$

\begin{tabular}{|c|c|c|c|c|c|}
\hline & Disturbance & Never & Occasionally & Quite Often & Very Often \\
\hline \multirow[t]{4}{*}{ Frequency } & Glare & 20 & 5 & 3 & I \\
\hline & Haloes & 7 & 8 & 9 & 5 \\
\hline & Starbursts & 17 & 8 & 4 & \\
\hline & Disturbance & Not at all & Mild & Moderate & Severe \\
\hline \multirow[t]{4}{*}{ Severity } & Glare & 20 & 6 & 2 & I \\
\hline & Haloes & 8 & 9 & 9 & 3 \\
\hline & Starbursts & 19 & 6 & 4 & \\
\hline & Disturbance & Not at all & A little & Quite & Very \\
\hline \multirow{3}{*}{$\begin{array}{l}\text { Degree of } \\
\text { Bother }\end{array}$} & Glare & 22 & 4 & 2 & I \\
\hline & Haloes & 12 & II & 2 & 4 \\
\hline & Starbursts & 23 & 4 & I & I \\
\hline
\end{tabular}

independence and satisfaction. We used the PRSIQ because it is very short, with relevant questions and is easy for patients to understand. In general, overall satisfaction with vision appears higher with trifocal IOLs than with extended depth of focus IOLs, primarily due to the better near vision. ${ }^{4}$

Quality of vision scores reported here were slightly higher (worse) than results from a recent study in Norway, ${ }^{10}$ but very similar to recently reported results in the $\mathrm{USA}^{20}$ and somewhat lower than reported results from a study in Portugal, ${ }^{21}$ all of which included the same questionnaire and IOL. It appears that responses may reflect different patient attitudes and expectations in different regions. This suggests that comparisons of questionnaire data from different regions may be less reliable. While relative values varied, in all four studies haloes were the most

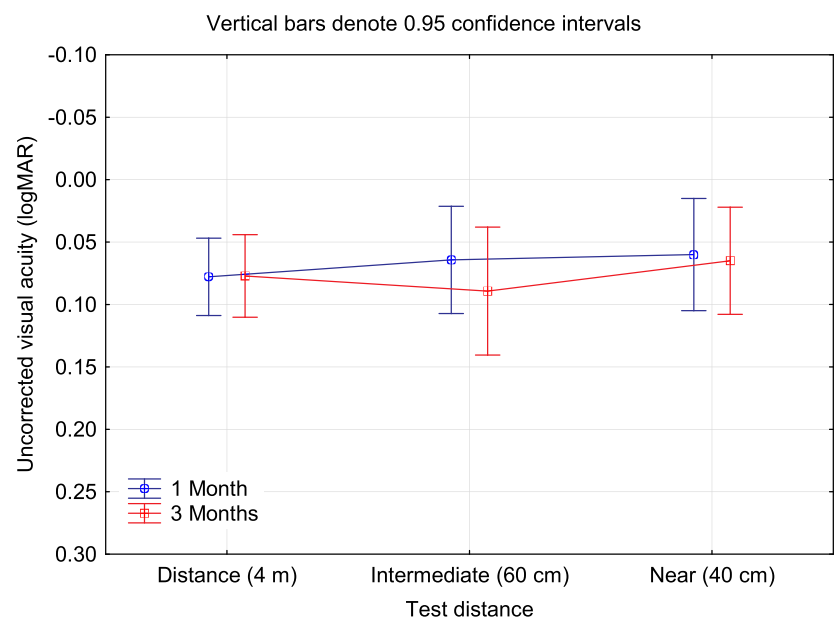

Figure 2 Binocular uncorrected visual acuity by test distance and postoperative visit.

Abbreviation: $\log M A R, \log$ of the minimum angle of resolution. frequently reported visual disturbance and reported as the most bothersome. The quality of vision scores here are also similar to those reported for other trifocal IOLs, and generally equivalent to or better than those reported with extended depth of focus (EDOF) IOLs. ${ }^{9,10,21}$ In all studies patient satisfaction with the trifocal IOL is high, indicating that there is an appreciated tradeoff between visual disturbances and good near vision.

As noted in the results, the outliers in the quality of vision data collected in the current study were associated with subjects who had postoperative dry eye; their reported satisfaction was also the lowest. This reiterates the need to identify and aggressively treat dry eye before and after cataract surgery with advanced technology IOLs. One recent study indicated that the cause of dissatisfaction

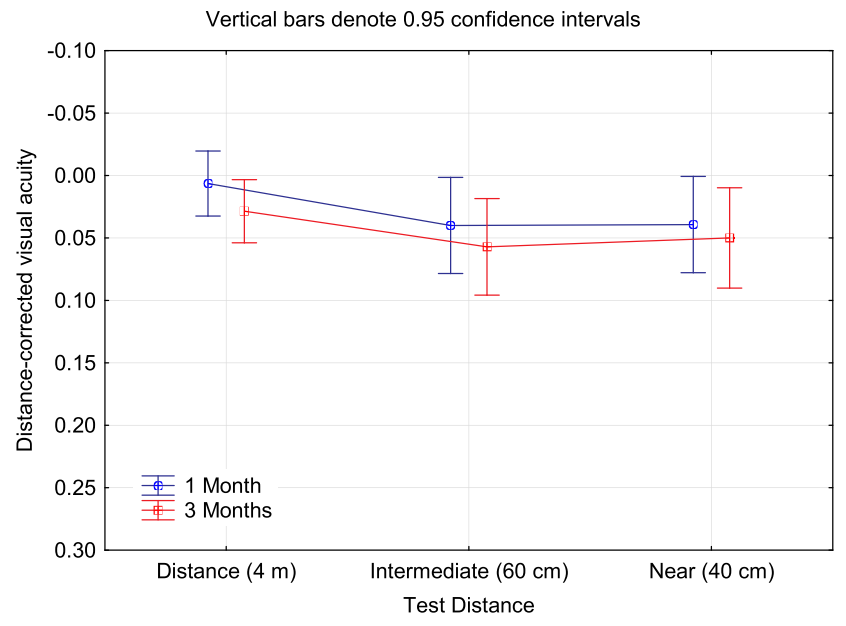

Figure 3 Binocular distance-corrected visual acuity by test distance and postoperative visit.

Abbreviation: $\log M A R, \log$ of the minimum angle of resolution. 
with presbyopia correcting IOLs could be traced to dry eye in $35 \%$ of subjects. ${ }^{22}$ Appropriate management of dry eye postoperatively can improve results in many patients. ${ }^{23}$

The binocular visual acuities reported here appear consistent with previous findings for the same IOL. ${ }^{4,5,24}$ Several studies have found, as in the current study, that intermediate VA was slightly worse than for both distance and near VA, but the relative differences reported were generally small (less than one line). ${ }^{17,22,25}$

There are limitations to the current study. It was conducted at a single site with a relatively small sample size. Objective quality of vision data such as contrast sensitivity or low contrast acuity were not collected. Finally, the study was a single-arm study, so no comparative data relative to other IOLs were collected.

In summary, the trifocal IOL evaluated in this study appears to be a good alternative for appropriate patients interested in reducing their overall dependence on spectacles for distance, intermediate and near work. As with all multifocal IOLs, potential patients should be advised of the increased likelihood of visual disturbances such as halos, relative to implantation of a monofocal IOL. The management of dry eye is also important.

\section{Acknowledgments}

Victoria Wiltshire, RN, MBA, of SightTrust Eye Institute provided data collection and study administration support for this study. This research was conducted with support from Alcon, in the form of an investigator-initiated study grant (IIT \# 51718703).

\section{Disclosures}

Richard Potvin is a consultant to Alcon and Carl Zeiss Meditec. The authors report no other conflicts of interest in this work.

\section{References}

1. Yoon $\mathrm{CH}$, Shin IS, Kim MK. Trifocal versus bifocal diffractive intraocular lens implantation after cataract surgery or refractive lens exchange: a meta-analysis. J Korean Med Sci. 2018. 33(44):e275.doi: 10.3346/jkms.2018.33.e275. PMID: 30369857. PMCID: PMC62 00906.

2. Martínez de Carneros-llorente A, Martínez de Carneros A, Martínez de Carneros-llorente P, Jiménez-Alfaro I. Comparison of visual quality and subjective outcomes among 3 trifocal intraocular lenses and 1 bifocal intraocular lens. $J$ Cataract Refract Surg. 2019;45 (5):587-594. PMID: 30853317. doi:10.1016/j.jcrs.2018.12.005.

3. Cochener B, Boutillier G, Lamard M, Auberger-Zagnoli C. A comparative evaluation of a new generation of diffractive trifocal and extended depth of focus intraocular lenses. J Refract Surg. 2018;34:507-514. doi:10.3928/1081597X-20180530-02
4. Rementería-Capelo LA, García-Pérez JL, Gros-Otero J, Carrillo V, Pérez-Lanzac J, Contreras I. Real-world evaluation of visual results and patient satisfaction for extended range of focus intraocular lenses compared to trifocal lenses. Int Ophthalmol. 2021;41(1):163-172. PMID: 32844238. doi:10.1007/s10792-020-01563-6.

5. Sheppard AL, Shah S, Bhatt U, Bhogal G, Wolffsohn JS. Visual outcomes and subjective experience after bilateral implantation of a new diffractive trifocal intraocular lens. $J$ Cataract Refract Surg. 2013;39(3):343-349. PMID: 23332118. doi:10.1016/j.jcrs.2012. 09.017 .

6. Mendicute J, Kapp A, Lévy P, et al. Evaluation of visual outcomes and patient satisfaction after implantation of a diffractive trifocal intraocular lens. J Cataract Refract Surg. 2016;42(2):203-210. doi:10.1016/j.jcrs.2015.11.037. PMID: 27026443.

7. Long J, Cheung R, Duong S, Paynter R, Asper L. Viewing distance and eyestrain symptoms with prolonged viewing of smartphones. Clin Exp Optom. 2017;100(2):133-137. PMID: 27716998. doi:10.1111/cxo.12453.

8. Kohnen T. First implantation of a diffractive quadrafocal (trifocal) intraocular lens. J Cataract Refract Surg. 2015;41(10):2330-2332. doi:10.1016/j.jcrs.2015.11.012. PMID: 26703312.

9. Ribeiro FJ, Ferreira TB. Comparison of visual and refractive outcomes of 2 trifocal intraocular lenses. J Cataract Refract Surg. 2020;46(5):694-699. doi:10.1097/j.jcrs.0000000000000118. PMID: 32358262 .

10. Gundersen KG, Potvin R. Trifocal intraocular lenses: a comparison of the visual performance and quality of vision provided by two different lens designs. Clin Ophthalmol. 2017;11:1081-1087.doi: 10.2147/ OPTH.S136164. PMID: 28652693. PMCID: PMC5472417.

11. Sezgin Asena B. Visual and refractive outcomes, spectacle independence, and visual disturbances after cataract or refractive lens exchange surgery: comparison of 2 trifocal intraocular lenses. $J$ Cataract Refract Surg. 2019;45(11):1539-1546. PMID: 31587938. doi:10.1016/j.jcrs.2019.06.005.

12. Alfonso JF, Fernández-Vega-Cueto L, Fernández-Vega L, Montés-Micó R. Visual function after implantation of a presbyopia-correcting trifocal intraocular lens. Ophthalmic Res. 2020;63(2):152-164. PMID: 31390634. doi:10.1159/000500834.

13. Alió JL, Plaza-Puche AB, Alió Del Barrio JL. Clinical outcomes with a diffractive trifocal intraocular lens. Eur J Ophthalmol. 2018;28 (4):419-424. PMID: 29619883. doi:10.1177/1120672118762231.

14. Bissen-Miyajima H, Ota Y, Hayashi K, Igarashi C, Sasaki N. Results of a clinical evaluation of a trifocal intraocular lens in Japan. Jpn J Ophthalmol. 2020;64(2):140-149. PMID: 31900871. doi:10.1007/ s10384-019-00712-4.

15. Morlock R, Wirth RJ, Tally SR, Garufis C, Heichel CWD. PatientReported Spectacle Independence Questionnaire (PRSIQ): development and validation. Am $J$ Ophthalmol. 2017;178:101-114. doi:10.1016/j.ajo.2017.03.018

16. McAlinden C, Pesudovs K, Moore JE. The development of an instrument to measure quality of vision: the Quality of Vision (QoV) questionnaire. Invest Ophthalmol Vis Sci. 2010;51(11):5537-5545. doi:10.1167/iovs.10-5341

17. Donmez O, Asena BS, Kaskaloglu M, Akova YA. Patients satisfaction and clinical outcomes of binocular implantation of a new trifocal intraocular lens. Int Ophthalmol. 2020;40:1069-1075. doi:10.1007/ s10792-020-01390-9

18. Modi S, Lehmann R, Maxwell A, et al. Visual and patient-reported outcomes of a diffractive trifocal intraocular lens compared with those of a monofocal intraocular lens. Ophthalmology. 2021;128(2):197-207. PMID: 33004211. doi:10. 1016/j.ophtha.2020.07.015.

19. García-Pérez JL, Gros-Otero J, Sánchez-Ramos C, Blázquez V, Contreras I. Short term visual outcomes of a new trifocal intraocular lens. BMC Ophthalmol. 2017. 17(1):72.doi: 10.1186/s12886-0170462-y. PMID: 28514944. PMCID: PMC5436431. 
20. Tran DB, Owyang A, Hwang J, Potvin R. Visual acuity, quality of vision, and patient-reported outcomes after bilateral implantation with a trifocal or extended depth of focus intraocular lens. Clin Ophthalmol. 2021;15:403-412. doi:10.2147/OPTH.S295503

21. Escandón-García S, Ribeiro FJ, McAlinden C, Queirós A, GonzálezMéijome JM. Through-focus vision performance and light disturbances of 3 new intraocular lenses for presbyopia correction. $J$ Ophthalmol. 2018:6165493.doi: 10.1155/2018/6165493. PMID: 29651343. PMCID: PMC5831879.

22. Gibbons A, Ali TK, Waren DP, Donaldson KE. Causes and correction of dissatisfaction after implantation of presbyopia-correcting intraocular lenses. Clin Ophthalmol. 2016;10:1965-1970.doi: 10.2147/ OPTH.S114890. PMID: 27784985. PMCID: PMC5066995.
23. Akman A, Asena L, Ozturk C, Gür Güngör S. Evaluation of quality of life after implantation of a new trifocal intraocular lens. J Cataract Refract Surg. 2019;S0886-3350(18)30998-2. doi:10.1016/j.jcrs.20 18.12 .003

24. Carreno E, Carreno EA, Carreno R, et al. Refractive and visual outcomes after bilateral implantation of a trifocal intraocular lens in a large population. Clin Ophthalmol. 2020;14:369-376. doi:10.2147/ OPTH.S238841

25. Ruiz-Mesa R, Abengozar-Vela A, Ruiz-Santos M. A comparative study of the visual outcomes between a new trifocal and an extended depth of focus intraocular lens. Eur J Ophthalmol. 2018;28:182-187. doi:10.5301/ejo.5001029

\section{Publish your work in this journal}

Clinical Ophthalmology is an international, peer-reviewed journal covering all subspecialties within ophthalmology. Key topics include: Optometry; Visual science; Pharmacology and drug therapy in eye diseases; Basic Sciences; Primary and Secondary eye care; Patient Safety and Quality of Care Improvements. This journal is indexed on PubMed
Central and CAS, and is the official journal of The Society of Clinical Ophthalmology (SCO). The manuscript management system is completely online and includes a very quick and fair peer-review system, which is all easy to use. Visit http://www.dovepress.com/ testimonials.php to read real quotes from published authors. 